\title{
Online Work Readiness Programme: Ready, Set, Go!
}

\author{
Belinda Janeke $e^{\mathrm{i}}$
}

\begin{abstract}
There has always been pressure on higher education institutions to enhance the employability of graduates and to instil knowledge, skills, and attributes that will be beneficial to future employers. The impact of Covid-19 on a global, national, and local level is placing even more pressure on the topic of employability. Graduates are uncertain about job availability and there is a need for career guidance. After a national and local shutdown of university campuses in 2015 and 2016 due to \#FeesMustFall, Career Services staff at the University of the Free State designed and created online work readiness programmes in order for students to continue with work preparations, no matter what the circumstances. In 2018, the first topics on CV-writing and job interview skills were rolled out online and made available to all registered students; each semester, two additional topics were added. By the time Covid-19 led to a national lockdown in South Africa in March 2020, the transition to online work readiness programmes was fairly easy. The purpose of this study is to determine the impact of the online work readiness programmes offered on the Blackboard platform from April to June 2020 during the Covid-19 pandemic and national lockdown. This article will provide an analysis of a questionnaire conducted with willing participants who have engaged and worked through the online work readiness programmes from April to June 2020, to investigate the impact on graduates' readiness for the world of work. Through the survey, students shared their learning experiences and the influence it has had on their career planning. It is believed that the findings of this research study will create a deeper understanding of how career services, as a particular functional area in student affairs, can reposition itself during uncertain times to remain responsive to the needs of students.
\end{abstract}

\section{Keywords}

career services; co-curriculum; Covid-19; employability; higher education institution; work readiness

\section{Introduction}

South African higher education institutions are under constant pressure to address a range of challenges, including unemployment, financial pressures for students and the sector, slow sectoral transformation, and the struggling economy of South Africa in general, which is exacerbated by the recent Covid-19 pandemic (Adotey, 2020; Heleta, 2016; Mutekwe, 2018; Roodt, 2020;Viljoen, 2018).

i Ms Belinda Janeke is the Head of Career Services, Student Affairs at the University of the Free State, South Africa.Email: janekeb@ufs.ac.za 
South Africa's economy has grown slowly in the past decade due to, amongst others, declining public finances, mass unemployment, and issues with power and electricity. During the Covid-19 pandemic, matters are worsening, with an expected negative growth of the economy that will most likely be contracting by 1-3\% before the end of 2020 (Roodt, 2020).

South African higher education institutions have been impacted by noticeable changes since the country became a democratic state in 1994. These include increased diversity in student and staff populations, advances in technology, learning strategies, and increased reflection on colonialism and how its many disguises as cultural, economic, political, and knowledge-based oppression still haunt the system (Heleta, 2016; Viljoen, 2018). Furthermore, student numbers have increased significantly, the need for formal qualifications has intensified - coupled with a decrease in funding, and changes occurred in curriculums and programmes (Chipunza \& Malo, 2017; Viljoen, 2018). In addition, the unemployment problem in South Africa is structural, in the sense that the majority of the labour supply (poorly educated workers) cannot find employment as there is little demand for low-skilled workers. However, the focus and mission of most higher education institutions are to address unemployment by providing high-skilled graduates for the workforce (Oluwajodu, Greyling, Blaauw \& Kleynhans, 2015).

Intensifying the pressure on higher education institutions, Mzileni (2020) highlights three additional problems that Covid-19 is bringing to the South African higher education context, namely: the lack of infrastructure for functional learning experiences; the movement towards online teaching and the struggle for students and staff to make the mind shift from the traditional teaching and learning contact to online learning; and thirdly, the dependence of undergraduates on face-to-face traditional teaching and learning practices to address their basic educational needs.

The South African government provided resources to the Department of Higher Education and Training (DHET) to develop the National Policy for an Integrated Career Development System for South Africa (DHET, 2017) in order to address three key priorities of the government, namely unemployment, poverty, and inequality. The vision of the policy is to assist South African citizens in accessing relevant post-school education and training, in order to fulfil the economic and social goals of participation in an inclusive economy and society (Career Development Services, 2017).

Career Services (CS - a division of Student Affairs) at the University of the Free State (UFS) supports the national policy by empowering and preparing students with the necessary transferable skills for the world of work. In 2017, employed UFS graduates indicated that they were very satisfied (31\%) and satisfied (42\%) with how the UFS had prepared them for employment (UFS Graduate Exit Survey, 2020). In a recent study conducted by Universum (2020) with more than 20000 experienced hires globally, only $27 \%$ of participants indicated that they felt their qualification offered them excellent preparation for their current position. Winani Ndlovu, Research Manager at Universum, denotes that these statistics exemplify the gap between academic learning and the world of work: 
With organisations now focusing on diversity and inclusion beyond the expected gender, age and ethnic background conversation, we are seeing their recruitment interests widen to cover talent with different knowledge and skillset backgrounds. Ultimately this might start shifting employer interests to those universities that offer blended learning that includes work-related work in an effort to push their students' preparedness for the world of work.

(Ndlovu, 2020)

These statistics exhibit a low satisfaction rate in terms of preparation to enter the world of work, corresponding with employers' experiences.

Employers believe that new employees - recent graduates in particular - lack basic skills, intellectual capacity, workplace skills, applied knowledge, and the ability to work effectively in the workplace (Oluwajodu et al., 2015). Globally, employers are struggling to find capable, adaptable, and skilled employees to keep up with this age of technology and the demands of the Fourth Industrial Revolution (Laubscher, 2018). A skilled workforce is needed to increase business productivity and competitiveness, which in turn will benefit the economy and reduce poverty (Laubscher, 2018). Another factor contributing to unemployment is job search activities, where job searchers are not investing time and effort to find the correct fit (Oluwajodu et al., 2015). Therefore, CS at the UFS embarked on this mission to not only develop workshops and training to address basic skills, workplace skills, and applied knowledge, but to also upscale the offering to serve approximately 40000 registered students by designing and implementing an online work readiness programme that students can engage with at any time.

\section{Employability and Work Readiness}

Entrenching employability, as suggested by the Higher Education Academy (HEA), concerns the provision of "opportunities to develop knowledge, skills, experiences, behaviours, attributes, achievements and attitudes to enable graduates to make successful transitions and contributions, benefiting them, the economy and their communities" (HEA, 2016, p. 1). The DHET (2017) emphasises their key priorities as addressing inequality, poverty, and unemployment. Therefore, South African universities are considered key players in addressing these three priorities in terms of quality of teaching and learning, attitude and values, actively encouraging and promoting co-curriculum participation, and the use of career services to enrich the employability of students (Walker \& Fongwa, 2017).

Work readiness refers to the level on which graduates are perceived to have the necessary attitudes, attributes, worker traits, and coping mechanisms to be successful in the workplace (Brady, 2010; Caballero \& Walker, 2010; Doe, 2015). The more work-ready a graduate is, having one or more workplace skills, the more employable and successful the individual will be in the workplace (Doe, 2015). Therefore, employability does not only mean being able to get a job, but to be able to implement work readiness skills in any given job.

CS at the UFS created, and continuously updates and improves, the work-readiness programmes delivered and offered to students, staying up to date with trends and demands 
from the world of work. The programme is practice-based and in the format of online work-readiness tutorials, content, and resources. The content is structured to suit the learning preferences of any student - from reading material to engaging activities, to easily accessible information in the form of infographics or checklists, and video recordings of the workshop content (UFS Career Services, 2020).

Challenges and opportunities presented themselves in October 2015 when the first campuses were shut down due to the \#FeesMustFall movement. It was during the 2015 and 2016 campus shutdown periods that CS at the UFS re-evaluated their offering to students, the delivery methods of crucial work-readiness programmes and information, as well as the access of students to internet-based platforms. In July 2018, CS rolled out a pilot study with the two most sought-after topics for work preparedness, namely CV-Writing and Job Interview Skills. The reasons and motivation for having online work-readiness programmes were three-fold: to embrace the multi-campus model of reaching all registered students of the UFS on all three campuses (approximately 40000 students); secondly, to deliver work-readiness programmes on a scale with a staff component of one full-time staff member; and lastly, in case of another campus shutdown, that work readiness programmes could be delivered hassle-free.

The national lockdown in South Africa due to Covid-19 once again created new challenges for both academic and support staff to continue academic and service delivery by means of online platforms. Fortunately, the CS at the UFS was ready to continue to work effortlessly, positioned with six topics to prepare students for the world of work. Indeed, from 27 March 2020, all face-to-face workshops were replaced with online programmes on different online platforms generated by the UFS.

Each topic was delivered online, with various options for students - from a step-bystep tutorial process, claiming badges and completing activities, to accessing cheat sheets or infographics, watching a short video recording on the topic, or viewing various resources and examples of profiles and CVs. Students' participation in the online workshops during Covid-19 provided an opportunity to evaluate the effectiveness of using different platforms.

\section{Conceptual Framework}

The Canadian Research Working Group on Evidence-Based Practice in Career Development (CRWG) has developed a framework for evaluating the delivery of careerrelated services and the effectiveness of career development interventions (Baudouin et al., 2007). Most formal research focuses on career development or counselling, and not specifically on the evaluation of career services or programmes and the impact these have on clients or students (Benzinger et al., 2011). This framework was developed after various evaluation models in literature were researched, considering the strengths and weaknesses of each model, and ultimately deciding to develop a framework that could be easily incorporated into practice, easily understood, and still included all relevant information to evaluate career interventions comprehensively (Baudouin et al., 2017). The framework consists of three elements, namely inputs, processes, and outcomes. 
The first element, inputs, refers to the resources available to assist clients to change and to reach the outcomes. Processes signify all mechanisms involved in achieving the outcomes. Outcomes relate to the changes experienced by clients and the results of the inputs delivered through the processes. The CRWG refers to the three elements as a linear process, but states that the relationship between the elements is not strictly linear due to the outputs being influenced by the available inputs, and the nature of the inputs that can impact the process used.

Inputs include the resources available to the institution to deliver quality services, namely staff, funding, service guidelines, facilities, infrastructure, and community resources. Table 1 below indicates the inputs of CS at the UFS, namely: staff, funding, service guidelines, and facilities.

Table 1: CS inputs

\begin{tabular}{|l|l|}
\hline Staff & $\begin{array}{l}\text { 1 full-time staff member, 1 contract appointment, and 5-10 volunteers per } \\
\text { semester. }\end{array}$ \\
\hline Funding & A budget of R100000 for student relations activities per annum. \\
\hline $\begin{array}{l}\text { Service } \\
\text { guidelines }\end{array}$ & $\begin{array}{l}\text { CS's mandate is to offer a range of services and resources designed to assist } \\
\text { students to develop the employability skills they need in today's world } \\
\text { of work. The Student Relations portfolio provides career development } \\
\text { and guidance to students and delivers work readiness programmes. The } \\
\text { Company Relations portfolio offers services to employers to advertise, } \\
\text { interview, and recruit talented students. }\end{array}$ \\
\hline Facilities & $\begin{array}{l}\text { Blackboard is used as the Learning Management System. Six topics were } \\
\text { planned and designed for online learning. Thirteen activities must be } \\
\text { completed in order to receive a badge (as part of gamification), of which } \\
\text { eight activities are automatically marked, and five activities must be } \\
\text { marked manually. }\end{array}$ \\
\hline
\end{tabular}

CS inputs do not include any additional infrastructure such as consultants or support staff, and do not have community resources such as a specific section in the library dedicated to career development, or computer rooms dedicated to career services.

The second element, processes, refers to the interventions and quality service factors. First of all, interventions consist of specific interventions (singularly focused on clients' goals and outcomes with the purpose of fostering change) and generic interventions (interactions of service providers or third parties). The other factor, namely quality service, refers to the tools for measurement. Although it may provide the outcomes for this process, it is still considered as part of the process indicating the effectiveness of the process. Table 2 below indicates the CS processes at the UFS, namely: specific interventions and quality of service. 
Table 2: CS processes

\begin{tabular}{|l|l|}
\hline Specific & $\begin{array}{l}\text { A work readiness programme addressing all six categories within } \\
\text { this framework, namely: career decision-making, work-specific } \\
\text { skills enhancement, work search, job maintenance, career-related } \\
\text { personal development, and other resources (referrals). The CS work } \\
\text { readiness programme consists of six topics, with activities to test } \\
\text { the knowledge gained, and practical submissions to be marked } \\
\text { manually by staff. The six topics are CV-writing, interview skills, } \\
\text { LinkedIn, digital world: personal branding for success, networking } \\
\text { and job-hunting skills, and future of work. }\end{array}$ \\
\hline $\begin{array}{l}\text { Quality of } \\
\text { service }\end{array}$ & $\begin{array}{l}\text { CS will determine the usefulness and impact of the online } \\
\text { work readiness programmes through evaluation by means of a } \\
\text { questionnaire sent to students. }\end{array}$ \\
\hline
\end{tabular}

CS processes do not include generic interventions provided by third parties or service providers.

The third element, outcomes, is concerned with the result of an intervention, including change in the client's competence, attributes, and broader changes for the client or community. The outcomes and results are organised into three categories, namely client learning outcomes, client personal attribute outcomes, and client impact outcomes. Table 3 below indicates the CS outcomes at the UFS, namely: student learning outcomes, student personal attribute outcomes, and student impact outcomes.

Table 3: CS outcomes

\begin{tabular}{|l|l|}
\hline $\begin{array}{l}\text { Student learning } \\
\text { outcomes }\end{array}$ & $\begin{array}{l}\text { The learning outcomes include the knowledge and skills that can } \\
\text { be directly linked to the programme or intervention used, including } \\
\text { personal management, learning and work exploration, or building a } \\
\text { life or career. }\end{array}$ \\
\hline $\begin{array}{l}\text { Student personal } \\
\text { attribute } \\
\text { outcomes }\end{array}$ & $\begin{array}{l}\text { Personal attribute outcomes include changes in attitude, } \\
\text { intrapersonal skills (self-esteem, motivation, and confidence), and } \\
\text { independence. }\end{array}$ \\
\hline $\begin{array}{l}\text { Student impact } \\
\text { outcomes }\end{array}$ & $\begin{array}{l}\text { Impact outcomes refer to the learning outcomes of interventions } \\
\text { and can contribute to changes in a client's life, such as employment } \\
\text { status, pursuing training, social and relational impact, and economic } \\
\text { impact. }\end{array}$ \\
\hline
\end{tabular}

It is important to note that all student relations projects and programmes in CS are planned and created in alignment with the UFS graduate attributes, which include critical thinking, problem solving, entrepreneurship, oral and written communication, ethical reasoning, and civic engagement (Strydom \& Oosthuizen, 2019). In addition, all six student outcome domains - according to the Council for the Advancement of Standards in Higher Education (CAS) - were addressed in the work readiness programme: knowledge acquisition, construction, integration and application; cognitive complexity; intrapersonal development; interpersonal competence; humanitarianism and civic engagement; and practical competence (CAS, 2015). 


\section{Methodology}

In order to evaluate the effectiveness of career development interventions in online form, a convergent mixed-method design was used for the study. This implied gathering both quantitative and qualitative data simultaneously, analysing the data sets separately, and then comparing the findings (Creswell \& Creswell, 2018). This approach was used to draw on the strengths of both quantitative and qualitative research, and to facilitate an in-depth understanding of the qualitative data to explain the quantitative database of the collected questionnaires (Creswell, 2014).

The questionnaire was guided by the CRWG framework and consisted of 74 questions, including closed-ended, Likert type, and open-ended questions. It should be noted that participants weren't expected to answer all 74 questions; the questionnaire started with 10 questions about the online format, followed by questions regarding the six topics. For each topic selected in question 1, the participant would've been asked eleven additional questions per topic. Each workshop had its own unique questions for evaluating the intended outcomes, followed by generic open- and closed-ended questions for all respondents, particularly focusing on their experiences with the online platform, the value of the workshops for their development, and recommendations they might have. The purpose of the evaluation questions was to determine students' experiences about the online process (user-friendliness), the teaching and learning component of each topic (whether they implemented the knowledge gained), as well as the content and resources (what they found useful and informative).

The questionnaire was done electronically by sending an email with the link to the selected participants. About 2869 students completed the online workshops between April and June 2020. Most of the students were between the ages of 18 and $23(n=2221), 60,3 \%$ were female, $86,3 \%$ were African, and the majority were undergraduates $(n=2533)$ from seven faculties, of which the Faculty of the Humanities $(n=830)$ was the best represented, followed by the Faculty of Natural and Agricultural Sciences $(n=588)$, and the Faculty of Economic and Management Sciences ( $\mathrm{n}=567)$. These students were purposefully sampled to provide feedback on their experiences with the workshops. Of the 2869 workshop participants, 116 completed the survey (response rate of 4\%). Although this response rate is not representative of the larger population, it would suffice to provide the CS with feedback on how the 116 students experienced the workshops in an online format, which would in turn contribute to future planning.

Data was analysed separately (quantitative and qualitative) and then merged to allow for a side-by-side comparison to determine similarities and elaboration on experiences, as well as how data related to one another (Creswell, 2014). Completed questionnaires delivered empirical data and were analysed using SPSS software that delivered descriptive statistics. The qualitative data were analysed through inductive and deductive content analysis by first identifying the extent to which the intended outcomes were mentioned by students in their provided text, followed by a more open reading of additional outcomes (Krippendorff, 2018). Through qualitative data, the following themes were identified that are aligned with the three outcomes of the conceptual framework used: student learning 
outcomes, students' personal attributes, and impact outcomes. Additionally, the online platform was evaluated, leading to the fourth theme. Each topic of the work readiness programme had specific student learning outcomes that were measured in this research. Qualitative feedback provided insight into students' personal attributes developed through engagement with the content, as well as feedback regarding impact outcomes indicating whether participants were encouraged to move into action by implementing what they have learned. Both quantitative and qualitative data provided insight into how the online format was experienced, used, and could be improved.

\section{Findings and Discussion}

The conceptual framework discussed above consists of three elements: inputs, processes, and outcomes. There is little to no control over the inputs (staff, funding, service guidelines, and facilities); the processes consist of the specific intervention implemented (online work readiness workshops consisting of six topics), and determining the quality of service by evaluating the questionnaire sent to active participants. During the data analysis process, the conceptual framework was used to identify whether participants have developed or reached the outcomes intended with the work readiness workshops, namely: student learning outcomes, student personal attribute outcomes, and student impact outcomes. The first part of the questionnaire asked participants to identify the topics they had completed, followed by general feedback regarding the course. Participants then had to answer evaluation questions per topic they have chosen. Table 4 below shows that $\mathrm{CV}$-writing was the topic most students participated in (67\%), followed by interview skills (37\%), networking and job hunting (35\%), LinkedIn (32\%), digital world: personal branding for success (31\%), and future of work $(29 \%)$.

Table 4: Workshops/topics completed

\begin{tabular}{|l|c|c|}
\hline Topic & Percentage* & $\begin{array}{c}\text { Number of } \\
\text { participants }\end{array}$ \\
\hline CV-writing & $67 \%$ & 61 \\
\hline Interview skills & $37 \%$ & 34 \\
\hline Networking and job-hunting skills & $35 \%$ & 32 \\
\hline LinkedIn & $32 \%$ & 29 \\
\hline Digital world: personal branding for success & $31 \%$ & 28 \\
\hline Future of work & $29 \%$ & 26 \\
\hline *Note: The majority of students participated in more than one workshop. \\
\hline
\end{tabular}

Participants indicated that the intended student learning outcomes were reached in every topic they engaged with online. The workshops created an understanding of each topic and the variety of resources contributed to participants' implementation of knowledge through the use of practical examples. In general, participants found the content easy to understand and experienced the content as adequate to assist them in preparing for a job interview, 
writing a $\mathrm{CV}$, and developing a personal brand, amongst others. They further agreed that they were confident to go for a job interview and answer questions to the best of their ability. Some examples of respondents' comments include:

It improved my knowledge of CV writing, cover letter design, my LinkedIn account, as well as the online presence. These are the factors potential employers are looking for. I was not able to achieve such a high standard without the help of this course.

(Participant 16; overall feedback regarding programme)

I now know the steps to have a good professional CV and cover letter, how to dress for work by keeping a personal brand, and how to prepare for a job interview.

(Participant 44; overall feedback regarding programme)

Participants found the activities in each topic very useful in terms of thinking critically about the implication of the specific topic on their career. For example, 78\% of participants in the CV-writing workshop found the CV-writing submission activity useful, and $77 \%$ of participants found the cover letter activity beneficial. Furthermore, in the interview skills workshop, 91\% of the participants agreed that the self-reflection activity assisted them to critically contemplate potential questions in a job interview as well as appropriate and professional answers, while an average of $84 \%$ of the participants experienced the networking and job-hunting activities as beneficial to making informed decisions, to critically think about the network they are building, and what kind of questions to ask during networking engagements.

Evidence shows that students' personal attributes were developed throughout the programme, linking to most of the UFS graduate attributes, as well as the six student outcome domains according to CAS standards (mentioned in the conceptual framework section). Evaluation data were categorised according to the six student outcome domains of the CAS standards, namely: knowledge acquisition, construction, integration and application; cognitive complexity; intrapersonal development; interpersonal competence; humanitarianism and civic engagement; and practical competence (Council for the Advancement of Standards in Higher Education [CASHE], 2015). It is important to note that evidence did not clearly reflect whether participants gained an understanding and appreciation of the humanitarianism and civic engagement, although these aspects were included in the step-by-step tutorials and activities.

Participants referred in various ways to their knowledge acquisition, construction, integration, and application that were supported and made possible by the format and layout of each workshop topic, and that led to self-reflection (CASHE, 2015). Example 1:

The cheat sheets are just to check quickly, the step-by-step is more in-depth, and the video is also more helpful as additional resource.

(Participant 11; CV-writing workshop)

The participant reflects on the use of one tool (cheat sheets) complemented by another (step-by-step tutorials) to provide depth to the understanding of the content and knowledge gained and refers to the video as an additional resource. This demonstrates the 
acquisition of knowledge through various resources, followed by the construction and integration of the knowledge to make sense of the topic at hand. Example 2:

It helped me to think of the image I am trying to put out there for my future employers.

(Participant 25; overall feedback regarding programme)

The participant's words "helped me to think" confirm the self-reflection that took place when engaging with the content, by thinking about a personal image and how this could influence a recruiter or potential employer. The knowledge acquisition, construction, integration, and application process address the need of employers to have employees who are capable of applying knowledge and skills (Oluwajodu et al., 2015).

Participants also referred to the workshops and platforms as supportive in navigating the cognitive complexity of content and better understanding the specific topic:

If I don't understand, I can replay the video again and again until I understand.

(Participant 104; networking and job-hunting workshop)

The videos gave me an idea of how I can submit relevant documentation to different employers.

Furthermore, the tutorials are clear, address the current trends, and have the ability to make students adapt quickly in the complex world.

(Participant 60; CV-writing workshop)

Both comments refer to the video recordings and resources as the tools these two participants used to critically and reflectively think about the content and then form an opinion and creative approach to a particular problem or challenge (CASHE, 2015). This correlates with the global perspective of employers struggling to find adaptable, skilled employees (Laubscher, 2018). The second comment addressed both the student learning outcomes and the impact outcomes that Participant 60 achieved.

Participants referred to the intrapersonal development and interpersonal competence they gained in order to communicate or participate in a job interview, how to be professional, and how to adapt to the changing world of work, for example:

I learnt that professionalism and how to carry yourself, speaks volumes for future employers.

(Participant 35; overall feedback regarding programme)

This remark corroborates Ndlovu's (2020) appeal to universities to offer blended learning that includes work-related work to prepare students for the world of work.

Arguably, the attribute most developed by students through the workshops is the confidence to implement learned objectives (practical competence). For example, 92\% of participants in the CV-writing workshop acknowledged their confidence to write a $\mathrm{CV}$ and $89 \%$ to write a cover letter. In the interview skills workshop, $88 \%$ of participants indicated their confidence to go for a job interview, and $94 \%$ were confident to answer questions during an interview. Furthermore, in the networking and job-hunting skills workshop, $87 \%$ of participants were confident to communicate and network with other people, $90 \%$ were confident to make informed decisions between two job offers, and $90 \%$ were confident to apply for jobs and to keep track of email communication, requirements per job, and progress with applications. All participants (100\%) in the future of work 
workshop indicated that they were confident to enter the world of work, recognising the importance of being flexible, and $96 \%$ were confident to expand their core skills, competencies, and mindset skills. In the digital world: personal branding for success workshop, all participants $(100 \%)$ were confident to use social media and online platforms to market their personal brand, and to build a good reputation in person and online. Lastly, $83 \%$ of participants in the LinkedIn workshop were confident about the appearance of their LinkedIn profile, 90\% knew how to use the job application tool, and 96\% were confident to use LinkedIn as a networking tool. The high percentages in all workshops mentioned above are representative of workshop outcomes reached, and the purpose of the work readiness programme met.

Some participants addressed the practical competence they gained throughout the programme, which is referred to as the impact outcomes. Participants reflected on how they updated their personal brands, CVs, LinkedIn profiles, and knowledge regarding workplace changes and technology. Some examples include:

I improved my CV, I am able to go for a job interview without being nervous. My LinkedIn account is up to date and I am not stressing to start working.

(Participant 11; overall feedback regarding programme)

I find it hard to talk to people. The workshop gave me courage to be the first one to start talking to people, asking relevant questions to know more about the industry I want to be in.

(Participant 44; networking and job-hunting workshop)

The video provided me with nice pictures that are accompanied with proper information explaining the slide to me. I preferred this method because 25 minutes later I knew what personal branding was as well as what not to do on my internet platforms.

(Participant 25; digital world: personal branding for success workshop)

These impact outcomes address the concern of unemployment raised by Oluwajodu et al. (2015) in linking unemployment with job seekers who do not invest time and effort to find the correct fit. It seems that participants grasped the content of each workshop topic, followed by critical thinking and reflection on the outcomes, such as the portrayal of their image online, networking abilities, or creating a LinkedIn profile, and then implementing it by making adjustments and decisions, or by creating that CV needed to apply for a job.

Regarding the online format, participants experienced the design as effective for selfstudy (89\%), they liked the 'look and feel' of the workshops (86\%), and most participants attempted to implement the knowledge they had acquired (87\%) to prepare for entering the world of work. Participants 'strongly agreed' with the notion that each topic addressed their needs for preparation to enter the world of work (91\%); they also liked having options (92\%) to learn about a certain topic (options between using a step-by-step tutorial, infographics and checklists, additional resources, or a video recording of the workshop). Because most students experienced the online format of the workshops as easy to navigate (81\%), the variety of electronic content helpful to learn about a specific topic (93\%), and the selections sufficient to learn about a topic through tutorials, videos, infographics, and/ or activities (91\%), it is evident that students received all the necessary information, even 
though not through face-to-face engagements. However, most students (74\%) still prefer face-to-face workshops, which could relate to the fact that the format of this online programme is new, and UFS students having voiced their struggles to adapt to online teaching and learning methods in general due to possible access or network issues. These findings are corroborated by Mzileni (2020), who highlights the three problems brought forward in higher education during Covid-19, namely: the lack of infrastructure for functional learning experiences; the movement to online teaching and the struggle for students and staff to make the mind shift from traditional teaching and learning contact to online learning; and the dependence of undergraduates on face-to-face traditional teaching and learning practices to address their basic education needs. This is also reflected by the mere $7 \%$ of the UFS student population who engaged with the CS work readiness programme between April and June 2020.

Each workshop was designed with a variety of digital tools to help students selfnavigate, including (but not limited to) step-by-step tutorials, cheat sheets, video recordings of the workshops, and examples of CVs, profiles, and interview questions. When asked which of these platforms were the most useful, students' responses varied within as well as between workshops. For example, while $71 \%$ of CV-writing workshop participants found practical examples most useful, $52 \%$ in the interview skills workshop found cheat sheets and the video recordings of the workshop most useful. In the network and job hunting, as well as the digital world workshops, most students (54\% and $72 \%$ respectively) favoured the step-by-step tutorials.

The qualitative data indicated that the workshops contributed to the management of participants' expectations of the workplace. Suggestions for all topics included the possibility to download videos for future use; to market this programme more; to include a variety of resources, such as more interview questions and possible answers; demonstrations of certain skills, such as a real job interview or a success story of students who used their personal branding to get a job. For the LinkedIn topic, participants suggested the inclusion of videos and information on how to navigate the platform, and how to establish and use connections.

\section{Conclusion}

CS's plan to move online after the 2015 and 2016 protests allowed time to plan, develop, organise, and implement topics. Every year, evaluation data is used to improve the topics over time, and when Covid-19 and the national lockdown happened, CS repositioned itself to use the opportunity to move completely online - with positive results, as confirmed by the data.

First, it is important to note the difficulties that students experienced with online teaching and learning due to a lack of resources such as computers, internet connectivity, and anxiety about the unknown. However, the 2869 students who did engage with CS's work readiness programme, appreciated the online format of the work readiness programmes, which included a variety of tools to self-navigate through the learning 
outcomes. This, together with the feedback on activities that allowed students to develop more skills and knowledge, ultimately led to the ability to implement what they have learnt.

The three overarching outcomes (student learning outcomes, personal attributes, and impact outcomes) have been achieved, with various suggestions addressing the need for more resources or demonstrations, which will be integrated into the programme going forward. For example, the one CAS standard domain of humanitarianism and civic engagement that has not been mentioned or consciously learned, should be addressed by, amongst others, incorporating information and examples of unfairness and inequality in the workplace, as well as how to address or resolve this.

The results of this study will be used to improve the online offering with more demonstrations and videos, additional content, and perhaps some peer learning activities to make the workshops more engaging. A more interactive approach might compensate for feelings of isolation when working through workshops alone. The gamification part of the work readiness programmes (offering badges for completion of each step-by-step tutorial) should also be highlighted and culminated into a co-curricular transcript explaining the skills gained. Furthermore, this offering should be explained to all faculties in order to obtain their support to implement this programme in the final-year and postgraduate curriculums. CS further considers having the work-readiness programme as an online offering only (which can be delivered on scale to the approximately 40000 UFS students), and rather using face-to-face time to address individual needs through appointments or classroom engagement, especially because of the lack of human resources (one permanent staff member responsible for student relations projects, workshops, and programmes).

Whereas some participants mentioned broader marketing of the programme, more attention should rather be given to campaigns for students about the link between employers' wants and needs, which are addressed in the online work readiness programme. Furthermore, CS will benefit by sharing some success stories to create awareness and peer approval. Using focus groups with willing participants can also provide in-depth feedback to improve the programme.

In light of the findings of the study, it is therefore crucial for CS to not only assist graduates to get a job, but also to equip them for the world of work by broadening graduates' knowledge and skillsets to enable them to make successful transitions to the workplace and contribute to the economy and their communities (HEA, 2016; Ndlovu, 2020). Recommendations for further research are the inclusion of focus groups to elaborate on the skills that graduates believe they need. Secondly, CS should host think tanks with students and employers to determine future topics and foci in order to expand the online work readiness programme. And finally, consider implementing all suggestions from participants in this study to improve the current offering, and then to re-evaluate it towards the end of 2020. It is believed that the findings of this research study will create a deeper understanding of how career services, as a particular functional area in student affairs, can reposition itself during uncertain times to remain responsive to the needs of students. 


\section{Research Ethics}

Ethical clearance was applied for and granted by the Ethics Committee of the University of the Free State, prior to the research. Student respondents indicated their willingness to partake in the study by means of informed consent on the questionnaire.

\section{Conflict of Interest}

The authors declare that they do not have financial or personal relationships that may have inappropriately influenced them in writing this article.

\section{Funding}

This work has not received any financial support.

\section{References}

Adotey, S.K. (2020). What will higher education in Africa look like after COVID-19? World Economic Forum, published on 8 June 2020. https://www.weforum.org/agenda/2020/06/higher-education-africacovid19-coronavirus-digital-online/ [Accessed 22 July 2020]

Baudouin, R., Bezanson, L., Borgen, B., Goyer, L., Hiebert, B., Lalande,V., Magnusson, K., Michaud, G., Renald, C. \& Turcotte, M. (2007). Demonstrating value: A draft framework for evaluating the effectiveness of career development interventions. Canadian Journal of Counselling and Psychotherapy, 41(3).

Benzinger, K., Kerford, K., Lumsden, L., Mahoney, K., Rodney, Y. \& Keates, C. (2011). Career centre evaluation: A practitioner's guide. Toronto, Canada: Canadian Education and Research Institute for Counselling (CERIC).

Brady, R.P. (2010). Work readiness inventory: Administrator's guide. http://jist.emcp.com/media/product attachments/files/w/o/work-readiness-inventoryadministrators-guide.pdf

Caballero, C. \& Walker, A. (2010). Work readiness in graduate recruitment and selection: A review of current assessment methods. Journal of Teaching and Learning for Graduate Employability, 1(1), 13-25. https://doi.org/10.21153/jtge2010vol1no1art546

Career Development Services (2017). Career Development Services Profile. https://www.careerhelp.org.za/ sites/default/files/cds_profile.pdf [Accessed 20 May 2020].

Chipunza, C. \& Malo, B. (2017). Organizational culture and job satisfaction among academic professionals at a South African university of technology. Problems and Perspectives in Management, 15(2), 148-161. https://doi.org/10.21511/ppm.15(2).2017.14

Council for the Advancement of Standards in Higher Education (2015). CAS learning and development outcomes. In J.B. Wells (Ed.), CAS professional standards for higher education (9th ed.). CAS.

Creswell,J.W. (2014). A concise introduction to mixed methods research. Sage.

Creswell, J.W. \& Creswell, J.D. (2018). Research design: Qualitative, quantitative, and mixed methods approaches (5th ed.). Sage.

DHET (Department of Higher Education and Training) (2017). Government Gazette, 20 April, 622(40795). Republic of South Africa.

Doe, R. (2015). Work readiness among graduate students. LSU Doctoral Dissertations. 1008. https://digital commons.lsu.edu/gradschool_dissertations/1008

Heleta, S. (2016). Decolonisation of higher education: dismantling epistemic violence and eurocentrism in South Africa. Transformation in Higher Education, 8. https://doi.org/10.4102/the.v1i1.9 
Higher Education Academy (2016). Framework for embedding employability in higher education. https:// www.heacademy.ac.uk/system/files/downloads/embedding-employability-in-he.pdf [Accessed June 2020].

Krippendorff, K. (2018). Content analysis: An introduction to its methodology. Sage.

Laubscher, E. (2018). Unskilled labour in South Africa. Medium. Published on 14 July. https://medium. com/@erichlaubscher1/unskilled-labour-in-south-africa-af56852ed443 [Accessed 22 July 2020].

Mutekwe, E. (2018). Unmasking the ramifications of the fees-must-fall-conundrum in higher education institutions in South Africa: A critical perspective. Perspectives in Education, 35(2), 142-154. https:// doi.org/10.18820/2519593X/pie.v35i2.11

Mzileni, P. (2020, April 23). How COVID-19 will affect students. Mail \& Guardian. https://mg.co.za/ education/2020-04-23-how-covid-19-will-affect-students/ [Accessed 17 April 2020].

Oluwajodu, F., Greyling, L., Blaauw, D. \& Kleynhans, E.P. (2015). Graduate unemployment in South Africa: Perspectives from the banking sector. SA Journal of Human Resource Management, 13(1), 1-9. https:// doi.org/10.4102/sajhrm.v13i1.656

Roodt, D. (2020). Coronavirus could sink South Africa's economy by 6\%. BusinessTech. https://business tech.co.za/news/business/382489/coronavirus-could-sink-south-africas-economy-by-6-dawieroodt/ [Accessed March 2020].

Strydom, J.F \& Oosthuizen, L. (2019). Developing UFS graduate attributes: Enabling graduates to compete globally and locally while enhancing academic quality. University of the Free State: Centre for Teaching and Learning.

UFS Career Services (2020). Work readiness tutorials: Career Services Blackboard page. University of the Free State.

UFS Graduate Exit Survey (2020). University of the Free State graduate exit survey: Employment-based report on the 2017 graduating cohort. University of the Free State.

Universum (2020). Universum talent research 2020: South African professionals. Universum.

Viljoen, D. (2018, March 1). Higher education: $A$ vast and changing future landscape. Fin24. https://www. fin24.com/Finweek/Featured/higher-education-a-vast-and-changing-future-landscape-20180228 [Accessed April 2020].

Walker, M. \& Fongwa, S. (2017). Universities, employability and human development. Springer. https://doi.org/ 10.1057/978-1-137-58452-6

\section{How to cite:}

Janeke, B. (2021). Online Work Readiness Programme: Ready, Set Go! Journal of Student Affairs in Africa, 9(1), 119-133. DOI: 10.24085/jsaa.v9i1.1432 